\title{
Frequency Dependence of Hearing Loss with Perforations
}

\author{
Bhusal CL, ${ }^{1}$ Guragain RPS, ${ }^{1}$ Shrivastav RP' \\ 'Department of Otorhinolaryngology, Institute of Medicine, Maharajgunj, Kathmandu, Nepal.
}

\begin{abstract}
This cross-sectional study was cnducted in different sizes of pars tensa perforation in patients with chronic suppurative otitis media (CSOM) tubo-tympanic type undergoing myringoplasty. A total of 50 patients were recruited from the outpatient Department of Otorhinolaryngology Head and Neck Surgery in TU Teaching Hospital from June 2003 to May 2004. Cases of CSOM tubo-tympanic type with dry central perforation, conductive type of hearing loss were subjected to myringoplasty. Preoperative audiometric evaluations were done. While operating under microscope diameter of perforations were measured and perforations were grouped according to the size.
\end{abstract}

This study showed that the hearing loss was found to be more at lower frequencies and less as the frequencies increased. Hearing loss is more marked at lower frequencies as compared to higher frequencies, irrespective any size or location of perforation of pars tensa.

Key words: Hearing loss, Myringoplasty, Tympanic membrane perforation

\section{INTRODUCTION}

Chronic suppurative otitis media (CSOM) is one of the most common ear diseases in developing countries. Ear diseases are quite common and important causes of the hearing disability in Nepal. CSOM is defined as "a persistent disease, insidious in onset, often capable of causing severe destruction of middle ear structure with irreversible sequale, which is clinically manifested with deafness and discharge for more than three months". ${ }^{1}$ The prevalence of deafness and ear disease surveyed in six districts in Nepal, revealed that prevalence of deafness was $16.6 \%$ of the general population in age group of 5 years and above. Of 15845 people examined in the survey, $7.2 \%$ were found to have CSOM of tubo-tympanic type and $0.9 \%$ atticoantral type. It also showed that about one-third of the preventable deafness was due to CSOM. $^{2}$

Perforation of the tympanic membrane (TM) can result from trauma, middle-ear disease or the treatment of middle-ear diseases. Perforation occur as a result of the disease process in chronic otitis media, which affects at least $0.5 \%$ of the population. ${ }^{3}$ CSOM can lead to conductive hearing loss up to $60 \mathrm{~dB}$, which constitutes a serious handicap. ${ }^{4}$

The factors influencing hearing in tympanic membrane perforation are thought to be size and locus. Bekesy ${ }^{5}$ studied the effect of extremely small perforations $\left(1 \mathrm{~mm}^{2}\right)$ on hearing of frequencies from 6.25 to $1600 \mathrm{~Hz}$, and found that the perforation affected only the frequencies lower than $200 \mathrm{~Hz}$. McCardle and Tonndorf published a study of the effect of tympanic membrane perforations on sound transmission using both observations on the cat and study of a model. They described a low frequency hearing loss similar to that described by Bekesy. ${ }^{6}$ Loss of sound transmission of $30 \mathrm{~dB}$ at $500 \mathrm{~Hz}, 27 \mathrm{~dB}$ at $1000 \mathrm{~Hz}$ and $25 \mathrm{~dB}$ at $2000 \mathrm{~Hz}$ (average $=27 \mathrm{~dB}$ ) was reported. This hearing loss corresponds closely to the values for perforations larger than 50 percent. $^{7}$
Correspondence:

Dr. Chop Lal Bhusal

Department of Otorhinolaryngology

Tribhuvan University, Institute of Medicine

Maharajguni, Kathmandu, Nepal.

Email: dr_clb@hotmail.com 
Perforations cause hearing loss which depends on frequency, perforation size and middle ear air space volume. ${ }^{8,9}$ Perforation-induced hearing loss is maximal at the lowest frequency, gradually decreasing to a steady one between $1500-4000 \mathrm{~Hz}$, and minimal at $8000 \mathrm{~Hz}{ }^{10}$

The outcome of the study will give better understanding of hearing loss due to perforation of the tympanic membrane and this will also help to manage such cases more efficiently.

\section{MATERIAL AND METHODS}

This cross sectional study was conducted among a purposive sample of first 50 consecutive patients who underwent myringoplasty in the Department of Otorhinolarygology - Head and Neck Surgery, Tribhuvan University Teaching Hospital, Kathmandu, Nepal form Jun 2003 to May 2004. Approval from ethical committee and patient consent were taken. Patients of both sexes who had dry ear and who gave the consent to participate in this study were included. Patients below 14 year of age, and with active disease, tympanosclerosis, revision myringoplasty, mixed or sensory neural hearing loss (SNHL), CSOM attico-antral type, ossicular chain fixation or disruption and patients in whom ossicular chain status could not be assessed were excluded from this study.

The pre-operative examination included history taking, and examination of the ears under microscope (EUM). Audiometric assessment was performed using a clinical audiometer calibrated according to International Organization for Standardization (ISO) standard in a sound treated room. A pure tone audiometry within one week prior to surgery was done at the frequencies of 250, 500, 1000, 2000, 4000 and $8000 \mathrm{~Hz}$. Air and bone conduction threshold were determined with appropriate masking technique whenever indicated. "Hearing level" was defined as the mean air conduction threshold at 500, 1000 and $2000 \mathrm{~Hz}$ and average of these frequencies were calculated to measure the hearing level. Pre-operative examination findings were reconfirmed by EUM during surgery. EUM and peroperative findings were recorded on a performa.

The site of perforation in observed $\&$ the size of the perforation were measured under microscope by placing over them a thin metallic rod of various lengths, from $4 \mathrm{~mm}$ to $10 \mathrm{~mm}$, graduated in $1 / 2 \mathrm{~mm}$. steps. The area was than calculated from the usual mathematical formula, $A=\pi b c / 4$, where $A=$ area of performation, $b=$ length of the minor axis and $\mathrm{c}=$ length of the major axis. Myringoplasty was performed through transcanal route, but if patient had with a narrow ear canal, or if the anterior rim of the drum was obscured by a prominent bony over hang, a post-aural route was preferred which enhanced the exposure in such circumstances. It was carried out under local anesthesia, using $2 \%$ xylocaine with 1:100,000 adrenaline.

Data processing and analysis were done by using computer software Statistical Package for Social Sciences (SPSS) version 11.5 and f-test, $t$-test and $x^{2}$-test were applied wherever necessary. $P$ values of less than 0.05 were considered to be statistically significant.

\section{RESULTS}

A total of 50 patients were enrolled in this study. The result of the study is shown in the following tables and figures.

Age and Sex Distribution

Majority of patients 35 (70\%) were in the $15-24$ years age group with $16(32 \%)$ males and $19(38 \%)$ females (Table 1).

\begin{tabular}{|lccc|}
\hline \multicolumn{4}{|c|}{ Table 1. Age and Sex Distribution $(\mathbf{n}=\mathbf{5 0})$} \\
\hline Age $^{*}$ & Male & Female & Total \\
$15-24$ & 16 & 19 & 35 \\
$25-34$ & 7 & 3 & 10 \\
$35-44$ & 2 & 3 & 5 \\
Total & 25 & 25 & 50 \\
\hline
\end{tabular}

* in years

\section{Chief Complaints}

All the patients complained of intermittent otorrhoea and hearing loss. Only $10(20 \%)$ of them complained of tinnitus in the affected ears (Table 2).

\begin{tabular}{|lc|}
\hline Table 2. Chief Complaints $(\mathbf{n}=\mathbf{5 0})$ \\
\hline Complaints & No. of patients \\
Discharge & 50 \\
Hearing Loss & 50 \\
Tinnitus & 10 \\
\hline
\end{tabular}

Frequency of various sizes of perforation Majority of the patients were of group-D (19/50), i.e. above $40 \%$ of perforation of TM, followed by group-B (13/50), ranging from $10-20$ percentage of perforation of tympanic membrane (Table 3 ). 
Table 3. Size of perforation $(n=50)$

\begin{tabular}{lc|} 
Size of Perforation & Frequencies \\
A $(0-10 \%)$ & 6 \\
B $(10-20 \%)$ & 13 \\
C $(20-40 \%)$ & 12 \\
D (above $40 \%)$ & 19 \\
Total & 50 \\
\hline
\end{tabular}

Size of Perforation and Hearing Loss

Maximum hearing loss of $43.8 \mathrm{~dB}$ was observed in group D perforations, where as $30.8 \mathrm{~dB}$ was observed in group A perforations. Irrespective of the group, the greater hearing loss was observed in $500 \mathrm{~Hz}$ and less in $2000 \mathrm{~Hz}$ frequency (Table 4). in anterior central perforation. There was no significant difference between big central perforation ( $45 \mathrm{~dB}$ ) and posterior central perforation $(43 \mathrm{~dB})$. Hearing loss was almost equal in anterior central perforation 29.17dB and central malleolor perforation $29.5 \mathrm{~dB}$. However, the hearing loss was greater in lower frequencies as compared to the higher frequencies irrespective of the site of perforation (Table 6).

Hearing Loss in different frequencies

The average $\mathrm{HL}$ in $50(100 \%)$ patients at $500 \mathrm{~Hz}$ was $46.40 \mathrm{~dB}$, at $1000 \mathrm{~Hz}$ was $38.00 \mathrm{~dB}$ and at $2000 \mathrm{~Hz}$ was 31.90. This shows that for each perforations, the hearing loss is greater in the lower frequencies and less hearing loss as the frequencies increase (Table 7, figure 1 ).

Table 4. Size of perforation $(n=50)$

\begin{tabular}{|c|c|c|c|c|c|c|c|}
\hline $\begin{array}{l}\text { Size of } \\
\text { perforation } \\
\text { in group }\end{array}$ & $\begin{array}{l}\text { No of } \\
\text { cases }\end{array}$ & & $\begin{array}{c}\text { Hearing loss } \\
\text { at } 500 \mathrm{~Hz}\end{array}$ & $\begin{array}{l}\text { Hearing loss } \\
\text { at } 1000 \mathrm{~Hz}\end{array}$ & $\begin{array}{l}\text { Hearing loss } \\
\text { at } 2000 \mathrm{~Hz}\end{array}$ & $\begin{array}{c}\text { Average } \\
\text { Hearing loss }\end{array}$ & $\mathbf{P}^{*}$ \\
\hline \multirow{2}{*}{ A } & \multirow{2}{*}{6} & Mean & 35.00 & 28.33 & 28.33 & 30.8167 & 0.272 \\
\hline & & SD & 3.162 & 6.831 & 11.690 & 5.24725 & \\
\hline \multirow{2}{*}{ B } & \multirow{2}{*}{13} & Mean & 43.46 & 36.15 & 31.15 & 36.8923 & 0.003 \\
\hline & & SD & 9.439 & 8.204 & 8.454 & 6.45012 & \\
\hline \multirow{2}{*}{$\mathrm{C}$} & \multirow{2}{*}{12} & Mean & 45.83 & 34.58 & 30.42 & 36.9167 & 0.0007 \\
\hline & & SD & 7.930 & 11.172 & 8.649 & 6.87655 & \\
\hline \multirow{2}{*}{ D } & \multirow{2}{*}{19} & Mean & 52.37 & 44.47 & 34.47 & 43.8316 & 0.0003 \\
\hline & & SD & 8.057 & 11.291 & 9.985 & 8.10000 & \\
\hline \multirow{2}{*}{ Total } & \multirow{2}{*}{50} & Mean & 46.40 & 38.00 & 31.90 & 38.8060 & 0.0001 \\
\hline & & SD & 9.638 & 11.294 & 9.470 & 8.19575 & \\
\hline$P^{*}$ & & & 0.000 & 0.004 & 0.464 & 0.001 & \\
\hline
\end{tabular}

* Chi-square test

Frequency of sites of perforation

Majority of the patients were of group III (20/50), followed by group IV (17/50) (Table 5).

\begin{tabular}{|lll|}
\hline Table 5. Size of perforation $(\mathbf{n}=\mathbf{5 0})$ & \\
\hline S.N. & Site of Perforation & Number \\
I & Anterior Central & 6 \\
II & Posterior Central & 7 \\
III & Central Malleolar & 20 \\
IV & Big Central & 17 \\
& Total & $\mathbf{5 0}$ \\
\hline
\end{tabular}

Site of Perforation and Hearing Loss

A maximum hearing loss of $45 \mathrm{~dB}$ was observed in big central perforation and minimum hearing loss of $31 \mathrm{~dB}$

\section{DISCUSSION}

Patients below 14 years of age were excluded because all myringoplasty was done under local anaesthesia, which is difficult to perform in this age group. For calculation of average hearing loss (air conduction threshold) three speech frequencies namely $500 \mathrm{~Hz}$, $1000 \mathrm{~Hz}$ and $2000 \mathrm{~Hz}$ were selected. Puretone threshold audiometry has become the standard behavioral procedure for describing audiometry sensitivity; therefore, pure tone audiometry had been used for assessment of hearing level in this study.

In this study the most commonly affected age group was $15-24$ years with 35 (70\%) patients. The reason could be that this age group is socially active and health conscious. The findings of this study are similar to that 
Table 6. Size of perforation $(n=50)$

\begin{tabular}{|c|c|c|c|c|c|c|}
\hline $\begin{array}{l}\text { Site of } \\
\text { perforation }\end{array}$ & & $\begin{array}{l}\text { Hearing loss } \\
\text { at } 500 \mathrm{~Hz}\end{array}$ & $\begin{array}{l}\text { Hearing loss } \\
\text { at } 1000 \mathrm{~Hz}\end{array}$ & $\begin{array}{l}\text { Hearing loss } \\
\text { at } 2000 \mathrm{~Hz}\end{array}$ & $\begin{array}{c}\text { Average } \\
\text { hearing loss }\end{array}$ & $p^{*}$ \\
\hline $\begin{array}{l}\text { Anterior } \\
\text { central } \\
n=6\end{array}$ & $\begin{array}{l}\text { Mean } \\
\text { Std. Deviation }\end{array}$ & $\begin{array}{l}35.00 \\
4.472\end{array}$ & $\begin{array}{l}29.17 \\
3.764\end{array}$ & $\begin{array}{l}29.17 \\
7.360\end{array}$ & $\begin{array}{l}31.0667 \\
3.11876\end{array}$ & 0.121306 \\
\hline $\begin{array}{l}\text { Posterior } \\
\text { central } \\
n=7\end{array}$ & $\begin{array}{l}\text { Mean } \\
\text { Std. Deviation }\end{array}$ & $\begin{array}{l}52.14 \\
6.362\end{array}$ & $\begin{array}{c}43.57 \\
11.443\end{array}$ & $\begin{array}{l}33.57 \\
8.018\end{array}$ & $\begin{array}{l}43.3000 \\
7.00666\end{array}$ & 0.002819 \\
\hline $\begin{array}{l}\text { Central } \\
\text { melleolar } \\
n=20\end{array}$ & $\begin{array}{l}\text { Mean } \\
\text { Std. Deviation }\end{array}$ & $\begin{array}{l}41.50 \\
7.090\end{array}$ & $\begin{array}{l}31.75 \\
7.304\end{array}$ & $\begin{array}{l}29.50 \\
9.305\end{array}$ & $\begin{array}{l}34.2300 \\
4.78023\end{array}$ & 0.0022 \\
\hline $\begin{array}{l}\text { Big central } \\
\mathrm{n}=17\end{array}$ & $\begin{array}{l}\text { Mean } \\
\text { Std. Deviation }\end{array}$ & $\begin{array}{l}53.82 \\
7.187\end{array}$ & $\begin{array}{c}46.18 \\
10.537\end{array}$ & $\begin{array}{c}35.00 \\
10.458\end{array}$ & $\begin{array}{l}45.0706 \\
7.61280\end{array}$ & 0.000002 \\
\hline $\begin{array}{l}\text { Total } \\
n=50\end{array}$ & $\begin{array}{l}\text { Mean } \\
\text { Std. Deviation }\end{array}$ & $\begin{array}{l}46.40 \\
9.638\end{array}$ & $\begin{array}{c}38.00 \\
11.294\end{array}$ & $\begin{array}{l}31.90 \\
9.470\end{array}$ & $\begin{array}{l}38.8060 \\
8.19575\end{array}$ & 0.00001 \\
\hline
\end{tabular}

${ }^{*}$ chi-square test

of Prasansuk et.al, who studied 30 ears of 15 patients aged between $13-25$ years of age. ${ }^{11}$

This study consists of 25 males and 25 female patients, the ratio being 1:1. A similar M:F ratio of $1: 1$ is reported by Yong. ${ }^{12}$

These result are consistent with the cat cochlear-potential measurements of McArdle and Tonndorf ${ }^{6}$ Kurger and Tonndorf ${ }^{13}$ and the umbovelocity measurements of Bigelow et.al. ${ }^{14}$ in rat, in all of which perforation in the TM produced their largest effects at the lower frequency. Similarly, the temporal bone measurement of Nishihara et.al. ${ }^{15}$ and the audiometric results of both Tavin etal. ${ }^{16}$ and Rosowski etal. ${ }^{17}$ show that tympanostomy tubes in the TM produced their largest losses at the lowest frequencies. The perforation induced loss was most prominent at the lowest frequencies and the loss decreased with increasing frequency in the audiometric data of Ahmad and Ramani. ${ }^{18}$

The findings of this study disagreed with the result of Bekesy ${ }^{5}$ in human, and the audiologic data of Austin. ${ }^{7}$ Bekesy in his study concluded that the perforation "had no noticeable effect on thresholds from 50 to $4000 \mathrm{~Hz}$ except to alter slightly the small deviation in the frequency function." As no further details are given, it is difficult to explain the clear difference between that observation and this present study.

Austin describes the frequency-dependence of loss with perforation sizes as - the presence of perforation does not significantly affect the frequency response of the middle ear, since a flat hearing loss was observed for the three frequencies studied as well as for each size of perforation. $^{7}$

Indeed the means of audiograms at 500, 1000 and 2000 $\mathrm{Hz}$ that Austin ${ }^{7}$ presents do not show appreciable frequency dependence. However, this study measurement with perforation sizes similar to Austin's sizes showed a clear frequency dependence.

\section{CONCLUSION}

The findings of this study showed that the hearing loss in different sizes and sites of tympanic membrane perforation is clearly frequency dependence. It showed that for all perforation sizes and locations, the hearing loss was greater at the lower frequency and lesser in higher frequencies i.e. 1000-2000 Hz. Irrespective of its sizes and locations.

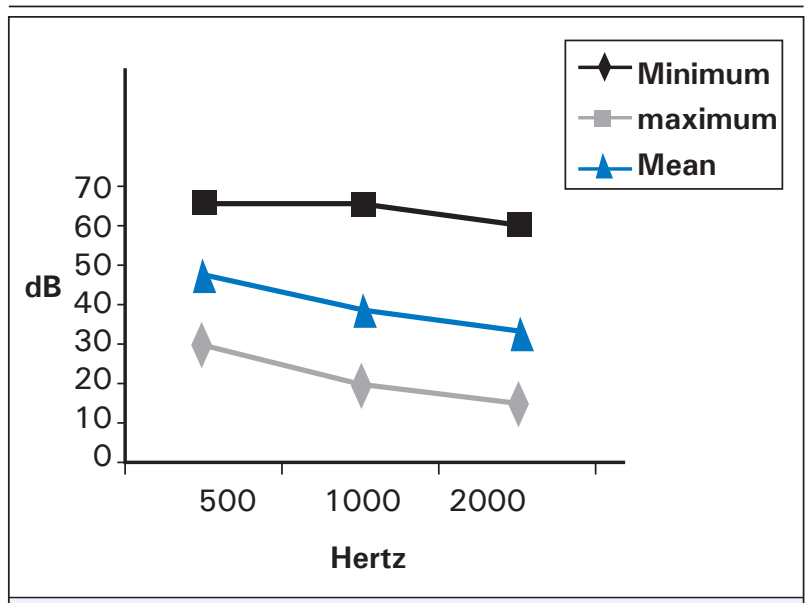

Figure 1. Hearing Loss in different frequencies (n-50) 


\section{REFERENCE}

1. Shenoi PM. Management of Chronic Suppurative Otitis Media. In: Kerr AG, BoothJB, editors. Scoot Brown's Otolaryngology, 35th ed. London, Butterworth and company; 1987; 215-237.

2. Guragain RPS. Survey of the Prevalence of Deafness and Ear diseases in Nepal. Echoes 1992;1:1.

3. Sade J. "Prologue", in procoedings of the second International conference of Cholesteotoma and mastoid surgery, edited by J Sade Kugler, Amsterdsm. 1982; p.1.

4. Voss SE, Rosowski JJ, Marchant SN, Peak WT. Acoustic responses of the human middle ear. Hearing Research 2000;150.

5. Bekesy GV. "Fur Physik des Mittebohres and Uber das Horen bei fehlerhaftem Trommelfell, Akust. F. 1936; 1: 13-23 (English translation, PP. 104:115 in Bekesy, 1960).

6. McArdle FE, Tonndorf J. Perforation of the Tympanic membrane and their effects upon middle-ear transmission. Arch Ohren Nasen Kehlkofheilkd 1968;192:145-162.

7. Austin DF. Sound conduction of the diseased ear. J Laryngol Otol 1978;92:367-93.

8. Anderson HC, Hansen CC, Neergaard EB. Effects of Tympanic membrane Perforations on hearing. Acta Oto-Larying 1964;56:307.

9. Voss SE Rosowski JJ, Merchant SN, Peake WT. Middle ear function with tympanic membrane perforations I: measurements and mechanisms. J Acoust Soc Am 2001;110:1432-44.
10. Ahmed SW and Ramani GV. Hearing Loss in perforations of the tympanic membrane. J Laryngol Otol 1979;93:1091-8.

11. Prasansuk S, Hinchcliffe R. Tympanic membrane perforation discriptors and hearing levels in otitis media. Audiology 1982; 21:43-51.

12. Yung MW. Myringoplasty: Hearing gain in relation to perforation site. J Laryngol Otol 1983;97:11-7.

13. Kruger B, Tonndorf J. Middle ear transmission in Cats with experimentally induced tympanic membrane perforations. J Acoust Soc Am 1977;61:126-32.

14. Bigelow DC, Swanson PB, Saunders JC. The effect of tympanic membrane perforation size on umbo velocity in the rat. Laryngoscope 1996;106:71-6.

15. Nishihara S, Aritomo H, Goode RL. Effect of changes in mass on middle ear function. Otolaryngol Head Neck Surg 1993 Nov;109(5):899-910.

16. Tavin ME, Gordon M, Ruben RJ. Hearing results with the use of different tympanostomy tubes: A prospective study. Int J Pediatric Otorhinolaryngology 1988;15:39-50.

17. Rosowski JJ, Merchant SN, Ravicz ME, Voss SE, Caradonna D, Cunningham MJ, et al. Analysis of acoustic mechanisms in middle-ear pathology and reconstruction. Laryngoscope. 1996; 183-90.

18. Ahmed SW, Ramani GV. Hearing Loss in perforations of the tympanic membrane. J Laryngol Otol 1979;93:1091-8. 